\title{
Mobile plants for plasma chemical water treatment
}

\author{
Michail Bruyako ${ }^{1}$ and Larisa Grigoreva ${ }^{1, *}$ \\ ${ }^{1}$ Moscow State University of Civil Engineering, Yaroslavskoe shosse, 26, Moscow, 129337, Russia
}

\begin{abstract}
Water is a valuable natural resource. It provides an exceptional role in metabolic processes, which are the basis of life. The negative factor of human activity is pollution of the environment, including water resources. Municipal sewage treatment is an urgent environmental problem. It exists both in Russia and abroad. Despite all the measures and methods used to treat wastewater, pollutants continue to flow into water bodies. The most dangerous pollutants are heavy metals, organic substances (proteins, fats, carbohydrates). To solve this problem, both traditional and modern methods are proposed. The purpose of this study is to develop an energy-efficient, eco-friendly mobile device for water purification based on the action of low-temperature nonequilibrium plasma. The developed installation has a small weight of 20 to $50 \mathrm{~kg}$, occupies a small area. To move it you can use any vehicle. Model samples and samples from the municipal sewerage network were prepared as experimental samples. The effect of low-temperature plasma showed a high degree of purification with a single exposure at low values of electric energy consumption per unit of water to be purified. Reduction of the concentration of ammonium-ion and ammonium nitrogen reaches $96-98 \%$.
\end{abstract}

\section{Introduction}

Use Every day, mankind spends up to 7 billion tons of water. The main consumers of water are such industries as chemical, petrochemical, pulp and paper, ferrous and nonferrous metallurgy, municipal services, agriculture (irrigation, animal maintenance). As a result of using water for industrial or domestic needs, sewage is formed. Wastewater is subject to disposal from the territory of populated areas and industrial enterprises.

In this connection, the question arises of the development of effective methods of water purification. Water treatment is a compulsory and costly measure, which is associated with a large variety of pollutants.

Methods of water purification include mechanical, chemical, hydromechanical, electrochemical, physico-chemical and biological effects.

Traditional biological methods of removing contaminants are in demand at the present time. Originally they were methods of natural cleaning with the help of activated sludge. Now, biological methods, this is an artificial process [1,2].

\footnotetext{
* Corresponding author: pehel@yandex.ru
} 
In work [3] the comparative analysis of traditional methods and modern with use of microalgae is resulted. The authors suggest that one of the promising directions in the purification of waste water is the use of algae to remove nitrogen, phosphorus, heavy metals. The authors of [4] showed that the removal of nitrogen, when using microalgae is from 72 to $83 \%$.

The main chemical pollutants in waste water are nitrogen and phosphorus. To remove these substances, combined cleaning methods are used.

The authors [5] tested the possibility of introducing an integrated stationary reactor with activated sludge. Removal of nitrogen was $82 \%$.

Sorption methods also have not lost their significance. The authors [6] presented a new nanomaterial, which has the ability to adsorb, precipitate. The use of nano- $\mathrm{CaO}_{2}$-coated clinoptilolite allows the precipitation of phosphates and the reduction of COD.

The study [7] is related to the development of a two-stage method for wastewater treatment. At the first stage, a membrane contactor system with a vacuum acceleration mode for the ammonia removal efficiency is proposed. In the second stage, a new biocomposite, an egg shell modified with iron oxide and zirconium, was investigated as an effective adsorbent of orthophosphates. The use of this method makes it possible to reduce the concentration of $\mathrm{NH} 4+$ by almost three times. The study was carried out at a temperature of $60^{\circ} \mathrm{C}$ and an initial $\mathrm{pH}$ of 12.0. The authors of [8] propose a method for wastewater treatment using ion exchange. Previously, water was passed through the membranes. Thus, the membrane technology was combined with ion exchange. At the same time, a reduction in COD of up to $65 \%$ was achieved.

The modern direction of research is related to the development of technologies aimed at energy and resource efficiency. The "green" technologies include plasma technologies. The authors [9] developed equipment and a new method for purifying water from biological and chemical impurities, based on the ignition of plasma in a water-aerated microporous medium. The mechanism of the formation of a cold plasma and the possibility of a method for creating mobile water purification devices are shown in [10].

Interest in plasma technology is due, firstly, to the fact that at very high temperatures it is possible to carry out processes that do not occur under normal conditions. This allows you to create materials with fundamentally new physical and chemical properties. Secondly, in a low-temperature plasma, the speed of chemical reactions is accelerated hundreds and thousands of times, which creates the preconditions for replacing bulky metallurgical and chemical installations with miniaturized, with an unprecedentedly high productivity. Thirdly, interest in plasma is also due to the possibility of creating one-stage, as a rule closed, technological cycles. This opens up broad prospects for the full automation of production and for solving the global problem - reducing the pollution of the air and water environment.

The purpose of this study is to develop an energy-efficient, eco-friendly mobile device for water purification.

In this connection, the MGSU worked on the development of a water treatment plant, which used the principle of the action of low-temperature nonequilibrium plasma.

\section{Materials and Methods}

During plasma treatment, water, pollutants interact with active and inactive plasma particles that have high kinetic or potential energy.

There are both physical and chemical principles of influence. In physical interaction, the particles have mainly kinetic energy, which can exceed the thermal energy by several orders of magnitude. Charged particles also have a high potential energy - recombination 
energy. In this connection, the particles acquire the ability to physically spray the material when colliding with the surface of solids.

In chemical interaction, active particles have a high potential energy. The interaction of such particles with the processed material leads to the formation of chemical compounds.

During the processing, it is impossible to completely separate the physical and chemical interactions, it is impossible to indicate any one process responsible for the effect of the plasma effect. Each of the processes carries elements of the other. The result of processing is due to the simultaneous action of various factors on the material and is determined by the parameters of the plasma being created.

However, in real processes of plasma treatment, one can single out the primary mechanism determining the efficiency of their flow. Depending on the properties of the low-temperature plasma and the charge state of the surface of the processed material, the main interaction mechanism and the kind of particles that contribute most to the surface modification are determined.

Model solutions with different content of basic chemical pollutants were prepared for the study. The samples of sewage taken from municipal sewerage networks were also subjected to the action of a low-temperature nonequilibrium plasma.

The content of ammonium ions [11], nitrite ions [12], nitrate ions [13], phosphate ions [14], chemical oxygen demand (COD) [15] was determined by the photometric method. The photometric method for determining the mass concentration of ammonium ions is based on the interaction of ammonium ions with potassium tetramericcurate in an alkaline medium (Nessler's reagent) to form a brown, water insoluble salt of the Milon base), which turns into a yellow colloid form with small ammonium ion contents. The optical density of the solution was measured at a wavelength of $425 \mathrm{~nm}$ in cuvettes with an absorbing layer length of 10 or $50 \mathrm{~mm}$. The photometric method for determining the mass concentration of nitrite ions is based on the ability of nitrites to react with sulfanilic acid to form the corresponding diazo compound, with further interaction with $\alpha$-naphthylamine a red azo dye is obtained. The optical density of the resulting colored solutions is measured on a spectrophotometer (photocolorimeter) at a wavelength of $520 \mathrm{~nm}$, in cuvettes with an absorbing layer length of 10 or $50 \mathrm{~mm}$, depending on the content of nitrites. The photometric method for determining the mass concentration of nitrate ions is based on the ability of nitrates to react with salicylic acid. The optical density of the resulting colored solutions is measured on a spectrophotometer (photocolorimeter) at a wavelength of 410 $\mathrm{nm}$. The photometric method for determining the mass concentration of phosphate ions is based on the interaction of orthophosphates with ammonium molybdate in an acid medium with the formation of molybdophosphoric acid, its reduction by ascorbic acid in the presence of antimony chloride followed by photometric measurement of the blue-colored reduced molybdophosphoric acid (molybdenum blue) at a wavelength $880-890 \mathrm{~nm}$. The photometric determination of bichromate oxidation (chemical oxygen consumption is based on the oxidation of organic substances and some inorganic substances by bichromate ion in an acidic medium when heated in the presence of silver sulfate, followed by a photometric measurement of the decrease in optical density of solutions at a wavelength of $450 \mathrm{~nm}$. The method consists in diluting the test sample with various volumes of specially prepared dilution water with a high content of dissolved oxygen, an infected aerobic E organisms with additives that suppress nitrification. The method for determining biochemical oxygen consumption [16] is based on the ability of microorganisms to consume dissolved oxygen in the biochemical oxidation of organic and inorganic substances in water. The decrease in oxygen content during a certain period of incubation in a dark place, at a control temperature, in a fully filled and hermetically sealed flask, is mainly due to bacterial biochemical processes taking place under aerobic conditions, which lead to mineralization 
of organic matter. The time required for complete mineralization depends on the nature of the organic matter.

After measuring the concentration of dissolved oxygen before and after the incubation period, the mass of oxygen absorbed from one $\mathrm{dm} 3$ of water is calculated. The oxygen decrease in the bottle, multiplied by the dilution rate, gives the numerical value of BOD, expressed in $\mathrm{mg} \mathrm{O}_{2} / \mathrm{dm}^{3}$.

\section{Results}

The principle of operation of the proposed mobile installation (Figure 1) for plasmachemical water purification is as follows: in the absence of mains power, the unit operates autonomously from a gasoline generator (with an output voltage of $220 \mathrm{~V}$ and a frequency of $50 \mathrm{~Hz}$ ). The gas generator is connected to a high-frequency power source, from which a low-temperature plasma generator is fed. By a water pump, waste water is supplied to the device (3), where the low-temperature plasma is affected by running sewage. After the action of the plasma, the water enters the container for purified water. Installation with a capacity of up to $500 \mathrm{l} /$ day is provided by a gasoline generator with a power of up to $5 \mathrm{~kW}$. In view of the impulse effect of electric discharge, the electricity consumption per $1 \mathrm{~m} 3$. The purified water is from 1 to $2 \mathrm{~kW} / \mathrm{h}$.

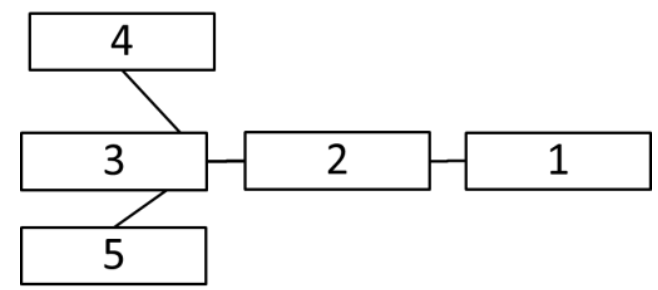

Fig. 1. Schematic diagram of a mobile plant for plasma chemical water treatment, where:

1 - Gas generator, 2 - High-frequency power supply, 3 - Device for generating low-temperature plasma, 4 - Water pump for sewage water, 5 - Capacity for purified water.

Table 1. Model solution

\begin{tabular}{|c|c|c|c|c|c|c|c|c|}
\hline \multirow{2}{*}{$\begin{array}{c}\text { Name of } \\
\text { indicators }\end{array}$} & \multirow{2}{*}{$\begin{array}{c}\text { Units of } \\
\text { measurement }\end{array}$} & \multicolumn{7}{|c|}{ Model solution } \\
\cline { 3 - 9 } & 1 & 2 & 3 & 4 & 5 & 6 & 7 \\
\hline $\begin{array}{c}\text { ammonium } \\
\text { ion }\end{array}$ & $\mathrm{mg} / \mathrm{dm}^{3}$ & 29.50 & 27.60 & 21.20 & 22.50 & 20.18 & 21.6 & 20.17 \\
\hline $\begin{array}{c}\text { ammonia } \\
\text { nitrogen }\end{array}$ & $\mathrm{mg} / \mathrm{dm}^{3}$ & 22.95 & 21.47 & 16.49 & 17.51 & 15.70 & 16.80 & 15.69 \\
\hline $\begin{array}{c}\text { phosphate } \\
\text { ion }\end{array}$ & $\mathrm{mg} / \mathrm{dm}^{3}$ & 3.1 & 2.8 & 2.8 & 2.7 & 2.5 & 2.4 & 2.2 \\
\hline $\begin{array}{c}\text { phosphorus } \\
\text { phosphate }\end{array}$ & $\mathrm{mg} / \mathrm{dm}^{3}$ & 1.01 & 0.91 & 0.91 & 0.88 & 0.81 & 0.78 & 0.72 \\
\hline COD & $\mathrm{mg} \mathrm{O} / \mathrm{dm}^{3}$ & 144 & 112 & 87 & 79 & 23 & 68 & 19 \\
\hline BOD 5 & $\mathrm{mg} \mathrm{O}_{2} / \mathrm{dm}^{3}$ & 121 & 95 & 77 & 71 & 17 & 55 & 15 \\
\hline
\end{tabular}


Preliminary tests were carried out on model solutions. The initial values of the chemical indices to be determined are given in Table 1 .

After a single exposure to a low-temperature nonequilibrium plasma, the content of ammonium ion decreased significantly by $90-98 \%$, ammonium nitrogen decreased to $94-$ $96 \%$. The decrease in $\mathrm{BOD}_{5}$ was $80-85 \%$. In a small amount, the content of phosphates decreased by $10-15 \%$.

Table 2 shows the results of a study of domestic wastewater. The selection is made from sewage treatment facilities of the rehabilitation department of the medical center.

Table 2. Analysis results protocol

\begin{tabular}{|c|c|c|c|}
\hline \multirow{2}{*}{ Name of indicators } & \multirow{2}{*}{$\begin{array}{c}\text { Units of } \\
\text { measurement }\end{array}$} & entrance & exit \\
\cline { 3 - 4 } & $\mathrm{mg} / \mathrm{dm}^{3}$ & 24.40 & 0.31 \\
\hline ammonium ion & $\mathrm{mg} / \mathrm{dm}^{3}$ & 18.98 & 0.24 \\
\hline ammonia nitrogen & $\mathrm{mg} / \mathrm{dm}^{3}$ & 81.75 & 35.79 \\
\hline nitrate ion & $\mathrm{mg} / \mathrm{dm}^{3}$ & 18.50 & 8.1 \\
\hline nitrogen of nitrates & $\mathrm{mg} / \mathrm{dm}^{3}$ & 2.26 & 2.2 \\
\hline phosphate ion & $\mathrm{mg} / \mathrm{dm}^{3}$ & 0.74 & 0.71 \\
\hline $\begin{array}{c}\text { phosphorus } \\
\text { phosphate }\end{array}$ & $\mathrm{mg} \mathrm{O} \mathrm{O}_{2} / \mathrm{dm}^{3}$ & 21.8 & 3.4 \\
\hline BOD & & & \\
\hline
\end{tabular}

Analysis of the obtained data shows that the decrease in the content of ammonium ions is $98 \%$, ammonium nitrogen $96 \%$, phosphate ion $16 \% \mathrm{BOD}_{5} 84 \%$.

The results of the action of a low-temperature nonequilibrium plasma on a model solution of "tap water-ammonium salt" are given in Table 3. Ammonium-ion, ammonium-nitrogen content below the detection limit (BDL)

Table 3. Analysis results protocol

\begin{tabular}{|c|c|c|c|}
\hline \multirow{2}{*}{ Name of indicators } & \multirow{2}{*}{$\begin{array}{c}\text { Units of } \\
\text { measurement }\end{array}$} & entrance & exit \\
\cline { 3 - 4 } & $\mathrm{mg} / \mathrm{dm}^{3}$ & 15.07 & BDL \\
\hline ammonium ion & $\mathrm{mg} / \mathrm{dm}^{3}$ & 11.72 & BDL \\
\hline ammonia nitrogen & $\mathrm{mg} / \mathrm{dm}^{3}$ & $\mathrm{BDL}$ & $\mathrm{BDL}$ \\
\hline nitrate ion & $\mathrm{mg} / \mathrm{dm}^{3}$ & 0.5 & 0.5 \\
\hline phosphate ion & $\mathrm{mg} / \mathrm{dm}^{3}$ & 0.17 & 0.16 \\
\hline $\begin{array}{c}\text { phosphorus } \\
\text { phosphate }\end{array}$ & $\mathrm{mg} \mathrm{O}_{2} / \mathrm{dm}^{3}$ & 1.7 & BDL \\
\hline BOD $_{5}$ & & & \\
\hline
\end{tabular}

\section{Conclusions}

The effect of low-temperature plasma showed a high degree of purification with a single exposure at low values of electric energy consumption per unit of water to be purified. The best results of the proposed method are achieved by reducing nitrogen in the analyzed waters. So, according to SanPin 2.1.4.1074-01 the maximum permissible concentration (MPC) for ammonium-ion is not more than $2.0 \mathrm{mg} / \mathrm{dm}^{3}$, we obtained the results of reduction to $0.31 \mathrm{mg} / \mathrm{dm}^{3}$.

The total weight of the installation is from 20 to $50 \mathrm{~kg}$ depending on the required capacity. In view of the small volume and the area occupied by such a facility, as well as its small mass, it is 
capable of being delivered to the place of use on any type of motor transport, which has significant advantages over existing manufactured analogues.

\section{References}

1. M. Chertkov A., Rus. Engineer 1 (7), 44-49 (2017)

2. Wastewater treatment using centralized drainage systems for settlements, urban districts (Moscow, BDT Bureau 2015)

3. P. Rajasulochana, V. Preethy, Res.-Ef. Technologies 2 (4), 175-184, (2016)

4. L. Delgadillo-Mirquez, F. Lopes, B. Taidi, D. Pareau, Biotechnology Reports 11, 18 26 (2016)

5. Y. Yang, L. Zhan, J. Cheng, S. Zhang, B. Li, Y. Peng, Bioresource Technology 239, 294-301 (2017)

6. K. Zhou, B. Wu, L. Su, X. Gao, X. Chai, X. Dai, Chem. Eng. J. 328 (15), 35-43 (2017)

7. D. Podstawczyk, A. Witek-Krowiak, A. Dawiec-Liśniewska, P. Chrobot, D. Skrzypczak, J. of Cleaner Production 161 (10), 277-287 (2017)

8. H. Gong, Z. Wang, X. Zhang, Z. Jin, C. Wang, L. Zhang, K. Wang, Chemical Engineering J, 311 (1), 13-19 (2017)

9. Yu. Velikodniy, M. Berkova, V. Vorotilin, V. Grishin, Ap. Physics 6, 105-110 (2008)

10. V. Odaruk, S. Tronin, Civil Security Technology 11, 3 (41), 46-51 (2014)

11. ERD F 14. 1:2:4.262-10 (Environmental Regulatory Document of the Federal level)

12. NDP 10.1:2:3.91-06 (Normative document of environmental protection)

13. ERD F 14.1:2:4.4-95(edition of 2011) (Environmental Regulatory Document of the Federal level)

14. ERD F 14.1:2:4.248-07 (Environmental Regulatory Document of the Federal level)

15. ERD F 14.1:2:4.210-05 (edition of 2013) (Environmental Regulatory Document of the Federal level)

16. ERD F 14.1:2:3:4.123-97 (edition of 2004) (Environmental Regulatory Document of the Federal level) 